\title{
Um pensador livre: "Não me pergunte quem sou eu" *
}

Pierre Bourdieu

Tradução de Fernando Pinheiro Filho

A proximidade objetiva não predispõe à percepção e à apreciação objetivas: não estou tão seguro de que, em matéria de conhecimento, haja um privilégio do compatriota, do contemporâneo, do condiscípulo e do colega. Francês, aluno da Escola Normal nos idos de 1945 no apogeu do existencialismo, professor de filosofia, Michel Foucault deve a esse enraizamento histórico seus pontos de partida, de referência, de ruptura, suas pegadas, seus faróis e fobias, tudo aquilo que contribui para constituir um projeto intelectual. A despeito de certa distância temporal, tenho em comum com ele todas essas propriedades determinantes e muitas outras que se seguem, notadamente na visão acerca do mundo intelectual. Não é por acaso que estivemos tantas vezes no mesmo lado, ou seja, aliados em face dos mesmos adversários e por vezes confundidos pelos mesmos inimigos. Também minha tentativa de contribuir para a justa compreensão de Michel Foucault e de sua obra, ao esboçar uma história intelectual do universo no qual e contra o qual seu pensamento se formou, expõe-se ao perigo da assimilação ou da dissimilação fictícias que, no caso de um pensador célebre, oferecem, uma e outra, importantes ganhos simbólicos.

No entanto a intenção se justifica, creio eu, a propósito de um intelectual que, como Michel Foucault, se empenhou em romper com a complacência narcísica do intelectual profético para conhecer não aquilo que ele tinha de singular, mas o que tinha de genérico, seu impensado de "pensador". Numa
* Agradeço a Jérôme Bourdieu a autorização para reproduzir este artigo. Publicado em italiano com o título "Non chiedetemi chi sono: un profilo di Michel Foucault", no periódico L'indice (Roma, outubro de 1984, pp. 4-5), foi redigido poucos meses após a morte de Michel Foucault, em 25 de junho de 1984. Uma primeira versão havia sido escrita por Bourdieu, intitulada "Le plaisir de savoir", e publicada no jornal Le Monde, em 27 de junho de 1984,pp. 1 e 10. Esta tradução para o português foi feita a partir do original em francês, "Une libre pensée", publicado anexo à biografia Michel Foucault, de autoria de Didier Eribon (2011) [N.E]. 
de nossas últimas conversas, em que evocávamos longamente, um para o outro, certas viradas decisivas de nosso itinerário intelectual, havíamos concebido o projeto de levar a cabo com um de nossos amigos comuns, Didier Eribon, diálogos em que seria evocado o mais sinceramente e o mais objetivamente possível, todo esse substrato inseparavelmente social e intelectual de uma empreitada de pensamento: encontros decisivos, leituras determinantes, recusas originárias, figuras exemplares. Coisas tão íntimas - e por vezes cuidadosamente dissimuladas, mesmo diante dos mais íntimos - que nos parecia bom dizê-las, torná-las públicas, como contribuição ao trabalho intelectual de clarificação do trabalho intelectual (a despeito de nosso horror compartilhado a qualquer forma de confissão pessoal).

Sem pretender desvelar minha intuição acerca do que poderia ser a "intuição central" da obra de Foucault, numa tentativa de apropriação de que todas as grandes obras são objeto, eu gostaria, ao evocar essa espécie de anticonformismo visceral, de impaciência recalcitrante com toda categorização e classificação, que definia Michel Foucault, de contribuir para protegê-lo contra a redução a uma ou a outra de suas propriedades classificatórias: historiador do conhecimento, historiador da ciência, historiador das ciências sociais, social scientist, filósofo, historiador da filosofia, filósofo da história, filósofo da história das ciências - nenhuma dessas etiquetas abusivamente restritivas saberia defini-lo. Lembrar sua relação com o marxismo ou com a tradição francesa de epistemologia (Bachelard, Canguilhem), de história da filosofia ou de história das ciências (Guéroult, Vuillemin), de antropologia ou de história estrutural (Lévi-Strauss, Dumézil), ou ainda com Nietzsche, Artaud ou Bataille, não implica reduzi-lo a "fontes" ou "influências", mas garantir os meios de captar as distâncias por intermédio das quais ele se construiu; não se trata de posicioná-lo na prisão classificatória com que se pretende confiná-lo, mas permitir-lhe escapar, como ele nunca deixou de fazer, como ele faria se estivesse ainda aqui; se trata de defendê-lo contra os classificadores, os burocratas do pensamento - Foucault é marxista ou antimarxista, ele é verdadeiramente um filósofo? - aquele que trabalhou com a energia derradeira e até o último momento explorando os limites (intelectuais e sociais) de seu pensamento, tomando distância de si mesmo e de seu pensamento - e com a imagem social de seu próprio pensamento.

Poderíamos começar com a relação com Marx e mostrar como essa tentativa de situar em termos materialistas o problema do conhecimento (uma das definições parciais possíveis do trabalho de Foucault) não se deixa reduzir à alternativa do marxismo e do antimarxismo, que ela não é nem um 
nem outro e ambos de uma vez. Se lhe ocorria de citar Marx, de tomar-lhe de empréstimo frases ou conceitos, não era nunca no registro que se impõe quando se quer ser considerado marxista, ou seja, alguém que reverencia Marx, celebrado pelos periódicos e revistas marxistas: na lógica da devoção, as citaçôes e as referências mais decisivas são as mais gratuitas, aquelas que estão lá, visivelmente, apenas para tornar a fé visível, professá-la, proclamá-la. Em vez da oblação teórica, Foucault prefere a homenagem discreta, mesmo secreta, que implica o uso, a aplicação. Esse lado crypto - teria ele vergonha de Marx, de dizer-se marxista, para assim fazer marxismo sem dizê-lo, e seria esse marxismo envergonhado ainda marxista? -, essa distância taxativa perante o culto ordinário - a que os althusserianos deram legitimidade intelectual -, essa maneira de fazer de Marx um autor como os outros, tudo isso desconcerta, inquieta mesmo os crentes. O mesmo com os filósofos: o mesmo Foucault que associava à descoberta verdadeira de Nietzsche a determinação de seu projeto intelectual diz, em algum lugar, que a única maneira de prestar homenagem a pensamentos como o de Nietzsche é utilizando-os, fazendo deles um uso qualquer, mesmo deformante - para escândalo dos comentadores.

Essa postura desenvolta em relação às identidades classificatórias nada tem de óbvia (basta pensar em Sartre, que consagrou o marxismo como "a filosofia insuperável de nosso tempo") e os ganhos intelectuais logrados se fazem acompanhar de perdas e custos sociais (e, claro, também inversamente: pensemos em todos que vivem e viveram das rendas asseguradas aos herdeiros legítimos da autoridade simbólica do momento, Marx decerto, mas também nos limites da universidade Kant, Heidegger ou mestres menores). Ao risco de parecer mudar de pato a ganso, evocarei aqui a relação com a política, outra dimensão da mesma postura profunda, e o horror a todas as formas do farisaísmo político que permite colher muitas vezes a preço irrisório as benesses ligadas à defesa de boas causas. Há sempre aqueles, mesmo entre os intelectuais, para quem é mais fácil dizer-se de esquerda quando a esquerda está no poder; para Michel Foucault e alguns outros, é mais difícil, senão impossível - para grande escândalo dos oportunistas, que denunciam "o silêncio dos intelectuais".

Mas é preciso seguir na obra mesma o diálogo com Marx (e, por tabela, com os "marxistas"), sempre presente em qualquer obra de ciência social. Em Loucura e desrazão, História da loucura na era clássica e em $O$ nascimento da clínica, Foucault vincula explicitamente o confinamento dos loucos nos asilos e dos pobres nos hospitais a uma teoria das relações de produção e a 
uma economia política da pobreza: os loucos incitam tratamento especial porque são os membros mais improdutivos da população; ao mesmo tempo, no início do liberalismo, o hospital e a clínica nasceram do valor de uso do corpo dos pobres:

Eis, portanto, os termos do contrato entre riqueza e pobreza na organização da experiência clínica. O hospital encontra aí, num regime de liberdade econômica, a possibilidade de interessar o rico; a clínica constitui a eliminação progressiva da outra parte contratante; ela é, por parte do pobre, o juro pago pela capitalização hospitalar consentida pelo rico.

A eufemização que o preciosismo do estilo carrega não chega a mascarar uma forma bastante brutal de economismo; o hospital é o lugar de uma troca desigual: o apaziguamento dado ao sofrimento contra um olhar clínico sobre o corpo exibido em espetáculo. Em Vigiar e punir, Foucault invoca explicitamente a análise marxista do capital constante e do capital variável para explicar a prisão moderna como instrumento do poder disciplinar e associa a acumulação de homens à acumulação do capital. Na História da sexualidade, ele vincula a disciplina e a regulação da sexualidade às exigências da produção, fazendo do poder sobre os corpos uma das condições do desenvolvimento econômico e da acumulação capitalista. Poderíamos assim multiplicar os textos que, tanto em seu modo de pensamento como em sua linguagem, possuem consonâncias fortemente marxistas.

A emergência do político em estado puro, com o conceito de "poder-saber", poderia, assim, aparecer como ruptura radical com a teoria marxista da dominação e com o economicismo que faz da propriedade dos meios de produção o princípio exclusivo (ou principal) da dominação: "o poder vem de baixo"; deixando de situá-lo num lugar central, o descobrimos em tudo, ou seja, em todos os lugares em que ele está, nas famílias, nos pequenos grupos, nos discursos, nas instituiçóes. Essa descoberta - o próprio Michel Foucault não o negaria - não deixa de estar referida a essa espécie de experimentação social que constituiu o movimento de maio de 1968: a disciplina moral do confinamento tinha a ver, mais do que dizia História da loucura, com os códigos disciplinares e o discurso. Mas de fato Foucault havia rompido, bem antes de Vigiar e punir, e sem dúvida desde o começo, com a teoria arquitetônica das instâncias hierarquizadas que os althusserianos reativaram tão fortemente (e que dominava todo o pensamento da escola dos Annales). Da análise da internação psiquiátrica à análise da normalização da sexualidade, trata-se sem- 
pre de mostrar, entre outras coisas, que fenômenos de pouca importância para os que adotam exclusivamente o ponto de vista econômico desempenham um papel capital na manutenção da ordem política, que poderia ser sua condição mais bem-oculta e a mais decisiva para o funcionamento da ordem econômica. O saber é um instrumento de poder, uma tecnologia social: repressão e proibição, exclusão e rejeição, tantas operações propriamente cognitivas de classificação que põem os indivíduos sob vigilância. A libido sciendi é uma libido dominandi que, como vemos no caso da clínica, é exercida sob as fachadas irrepreensíveis da vontade de saber.

Ao converter a história científica do conhecimento numa dimensão da ciência política, Foucault transforma radicalmente a intenção de Bachelard ou de Canguilhem justo no que ela tem de mais novo e de mais específico. Um e outro haviam buscado na história dos erros ou das falsas ciências (ver, por exemplo, Canguilhem, 1977) a verdade do trabalho científico, que não consegue revelar a reflexão de tipo kantiana sobre a ciência já feita, acabada. A ciência como "poder-saber" está sempre exposta à tentação do erro, que encontra seu princípio numa vontade de saber carregada de vontade de potência. Isso se vê melhor no caso das ciências sociais, sobretudo na fase inicial da qual elas ainda não se livraram, e não é para menos: medicina clínica e psicopatologia, direito e ciência política, Foucault estuda as ciências em que a fronteira entre a verdade e o erro é a mais frágil, as mais impregnadas de ideologia porque os móveis políticos que elas manipulam são infinitamente mais vitais do que aqueles das ciências da natureza. Ao tomar como objeto os domínios abandonados pelos historiadores - o hospital, a prisão ou o confessionário - e essas espécies de anti-heróis que os franceses chamam de "rebotalhos da humanidade" (criminosos, hermafrodita ou criança selvagem), Foucault se empenha em descobrir o impensado da ciência normal. Esse projeto se perfaz logicamente numa história social da ciência social, o "saber-poder" por excelência. Nesse ponto revela-se o projeto crítico - no sentido de Kant, cuja Antropologia Michel Foucault traduziu para o francês - que orienta todo o empreendimento. A crítica do conhecimento antropológico completa-se pela análise das condiçôes sociais e lógicas que tornam possível a ciência do homem pelo homem, isto é, na história da invenção histórica do homem. A genealogia histórica que, ao romper com o antropocentrismo da filosofia clássica, reconstitui a gênese social do homem moderno realiza por meios totalmente distintos a ambição kantiana de conhecer a capacidade de conhecer, isto é, essas tecnologias inseparavelmente políticas e cognitivas, essas disciplinas cuja aparição é contemporânea da industrialização e que funcionaram, sob aparência reformista, 
como instrumentos de polícia e de política, como regras de conhecimento e regras de vida, psicologia, medicina clínica, psicopatologia, ciências sociais, criminologia, teoria da população, economia política, psicanálise, psiquiatria. Figura exemplar, o olhar médico é estruturado não apenas pelo sistema de saberes que mobiliza, mas também pela relação social de dominação na qual ele se realiza: há uma "história política da produção da verdade".

Essa história social da produção do homem que se realiza por meio da luta pela produção da verdade sobre o homem é uma forma - senão a forma por excelência - do conhecimento de si. E a genealogia do conhecimento encontra seu prolongamento lógico numa "genealogia da moral". Explorar de um lado os limites sociais do conhecimento ou, o que dá no mesmo, as condiçôes sociais de possibilidade do conhecimento - notadamente do mundo social - que nos fornecem os "saberes-poderes" e as disciplinas, explorar de outro lado os limites sociais da moral, a gênese histórica desse "sujeito" que o antropocentrismo da filosofia clássica aceitava como um começo absoluto: eis aí duas realizaçóes da mesma intenção crítica. Nos dois casos, a reflexão sobre o limite introduz uma reflexão sobre os limites da reflexão. O poder, ou seja, a política, não está ausente da relação em aparência a mais íntima, a mais liberta de toda constrição e de todo controle social, o conhecimento reflexivo de si. O conceito de "saber-poder" visava lembrar que o saber está no poder e o poder no saber. E também assim no caso do saber sobre si. Destruir o antropocentrismo é conhecer e reconhecer o limite antropológico e proibir-se de projetar o homem no lugar deixado vazio pelos deuses mortos (ao modo, de certa forma exemplar, de Sartre, que pretendia restituir ao homem o poder de criação das verdades e dos valores que Descartes havia conferido a Deus).

História da sexualidade faz a história da gênese da consciência, do "sujeito" como consciência de si do desejo. Consciência infeliz: o "cuidado de si" é antes cuidado ético, que se constitui desde a Antiguidade, em torno do problema "privilegiado" - por quê? - da sexualidade e que se completa com o cristianismo. O sexo é o produto de uma história durante a qual o corpo é dividido contra si mesmo, pelo conhecimento pervertido de si que o discurso normalizador the oferece: histeria, onanismo, fetichismo $e$ coito interrompido são as quatro figuras exemplares do reino da norma política sobre a intimidade dos corpos. A subjetividade é filha do confessionário (o que explica, talvez, a fascinação que exerceu sobre toda uma geração impregnada pela baboseira personalista, a nova ciência do homem tal como a encarnava Lévi-Strauss, que abolia o sujeito). Esse sujeito que a antiga 
filosofia situava no começo é o produto da sujeição; ele nasceu, como a "sexualidade", da interiorização dos limites, aceitos ou transgredidos, cuja gênese era descrita pela história das disciplinas.

O projeto crítico, genealogia histórica do "sujeito" assujeitado, é inseparavelmente um projeto científico e político: o conhecimento antropológico é sem dúvida a única chance que temos de nos livrar do "sono antropológico" e de todas as formas de autocomplacência nascidas do cuidado de si, de nos liberar dos limites inerentes à ilusão do pensamento sem limites históricos, do pensamento sem impensado, de produzir, em uma palavra, um sujeito de que seríamos por pouco que seja os sujeitos. A teoria, essa visão que desvela, que põe a nu o poder, é uma prática, e uma prática política. Ela não pretende dizer o todo, a verdade total sobre o todo. Ela desentoca o poder de onde ele está, por vezes muito bem-escondido, nos nadas mais insignificantes da ordem ordinária, aceito como evidente. Ao romper com a representação - característica do homo academicus e notadamente do filósofo universitário - que leva a segmentar a vida em duas partes, aquela do conhecimento, investida pelo rigor, e aquela da política investida pela paixão, de preferência generosa, Michel Foucault concebeu a atividade intelectual como a forma por excelência de um empreendimento político de libertação: a política da verdade, que é a função própria do intelectual, se realiza num trabalho para descobrir e declarar a verdade da política. Isso é o que faz do desejo (perverso) de saber a verdade do poder um adversário irredutível do desejo de poder ${ }^{1}$.

\section{Referências Bibliográficas}

ERIbOn, Didier. (2011), Michel Foucault. Paris, Champs/Flammarion.

CAnguilhem, Georges. (1977), Ideologia e racionalidade nas ciências da vida. São Paulo, Edições 70.
1. Há cerca de um ano, no auge do debate em torno do "silêncio dos intelectuais", havíamos definido o projeto de um livro coletivo sobre o estado da política e da sociedade na França. Michel Foucault trabalhava, nessa perspectiva, numa história do discurso socialista. 